\title{
Novel lumen-apposing stent to treat benign esophageal stricture
}

A 58-year-old patient underwent an esophageal epiphrenic diverticulum resection with a video thoracoscopic approach. The surgery was complicated by an esophageal pleural fistula, which was successfully treated using a fully covered self-expandable metal stent. One week after stent removal the patient experienced dysphagia and vomiting. The endoscopy showed a short esophageal stenosis in the proximal esophagus about $25 \mathrm{~cm}$ from the dental arch ( Fig. 1 a).

Two consecutive endoscopic hydropneumatic balloon dilations of the stenosis were attempted but failed, as the stenosis recurred.

In order to achieve the desired dual effect of maintaining the patency of the esophageal lumen while continuing dilation, we decided to place a novel lumen-apposing fully covered metal stent (Spaxus stentbody diameter $16 \mathrm{~mm}$, flare diameter $31 \mathrm{~mm}$, length $20 \mathrm{~mm}$; Taewoong Medical Co., Gyeonggi-do, South Korea) (> Fig. 2).

Under endoscopic and fluoroscopic guidance, we released the stent across

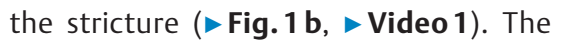
contrast dye injection showed correct placement of the stent, which kept the esophageal lumen open. The patient was fed a liquid diet 24 hours later, and 1 week later, the patient started a semiliquid diet.

At 2 months after stent placement, using crocodile tooth forceps, we grasped the knot situated in the proximal flange of the stent and retrieved

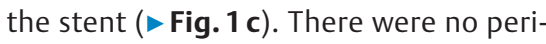
procedural or delayed adverse events. Following removal of the stent, the patient was put on a normal diet. The post-treatment 6-month follow-up showed no recurrence ( $\boldsymbol{F}$ Fig. $\mathbf{1} \mathbf{d}$ ).

Refractory benign esophageal strictures can be a challenge for clinicians. After failure of standard therapeutic options,

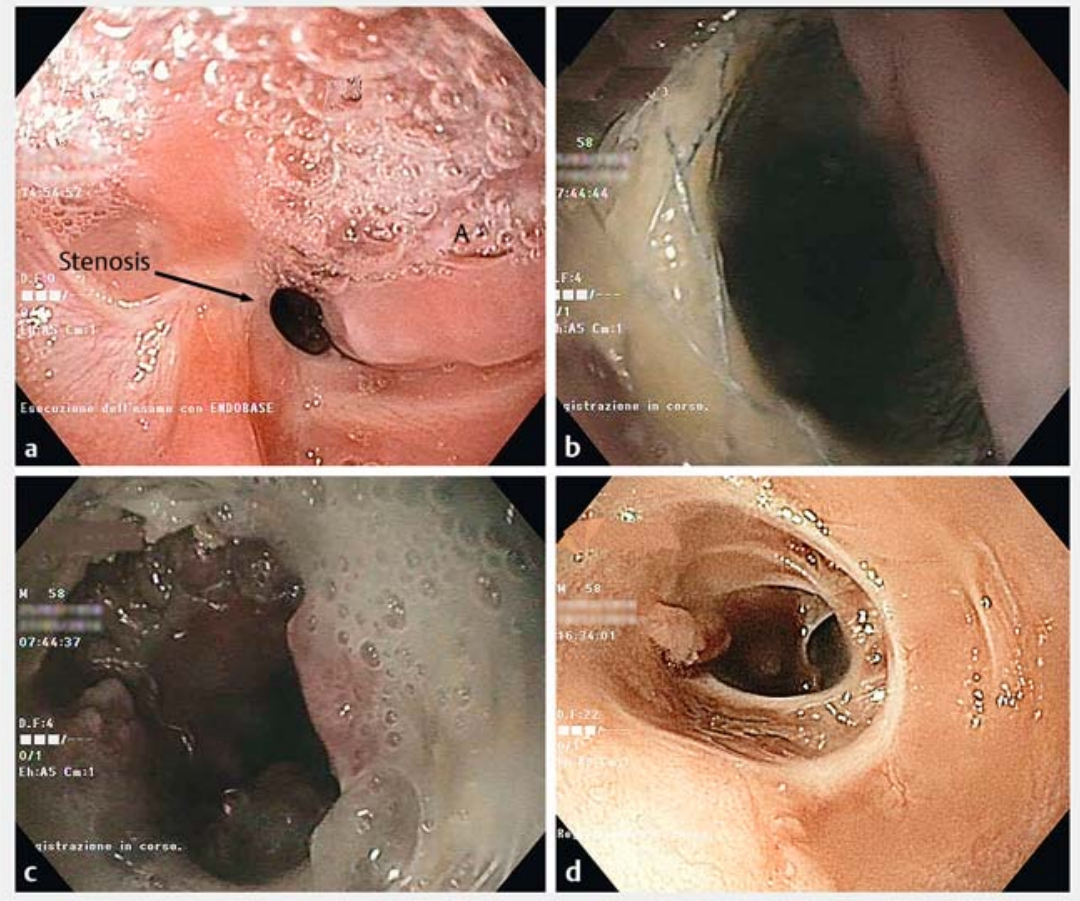

- Fig. 1 Endoscopic view of esophageal stenosis. a Short esophageal stenosis. b Proximal flange of the released stent. c Dilated stricture after stent removal. d Post-treatment 6-month follow-up.
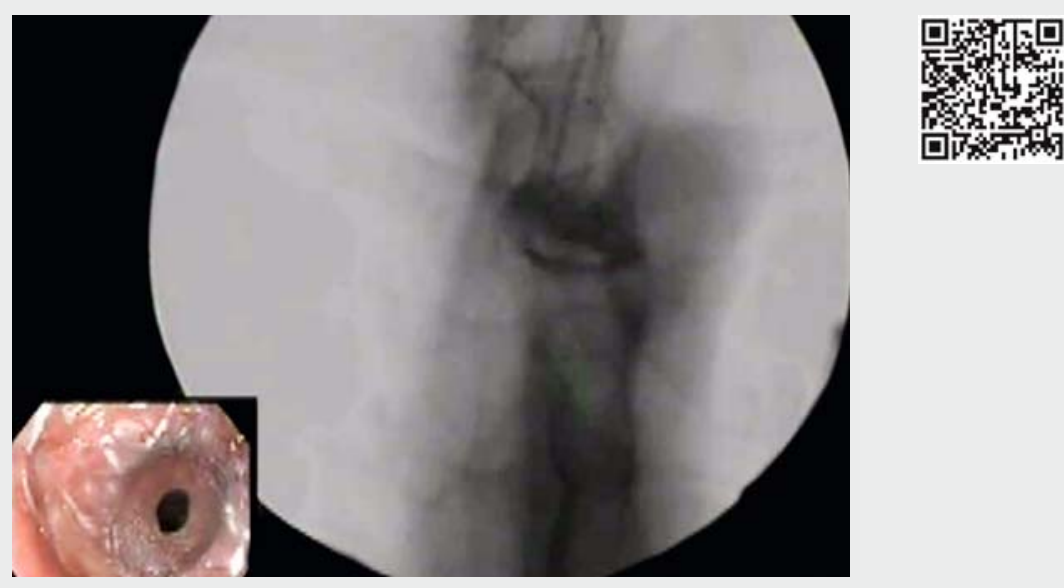

Video 1 Refractory benign esophageal strictures treated using a lumen-apposing stent (Spaxus; Taewoong Medical Co., Gyeonggi-do, South Korea). 


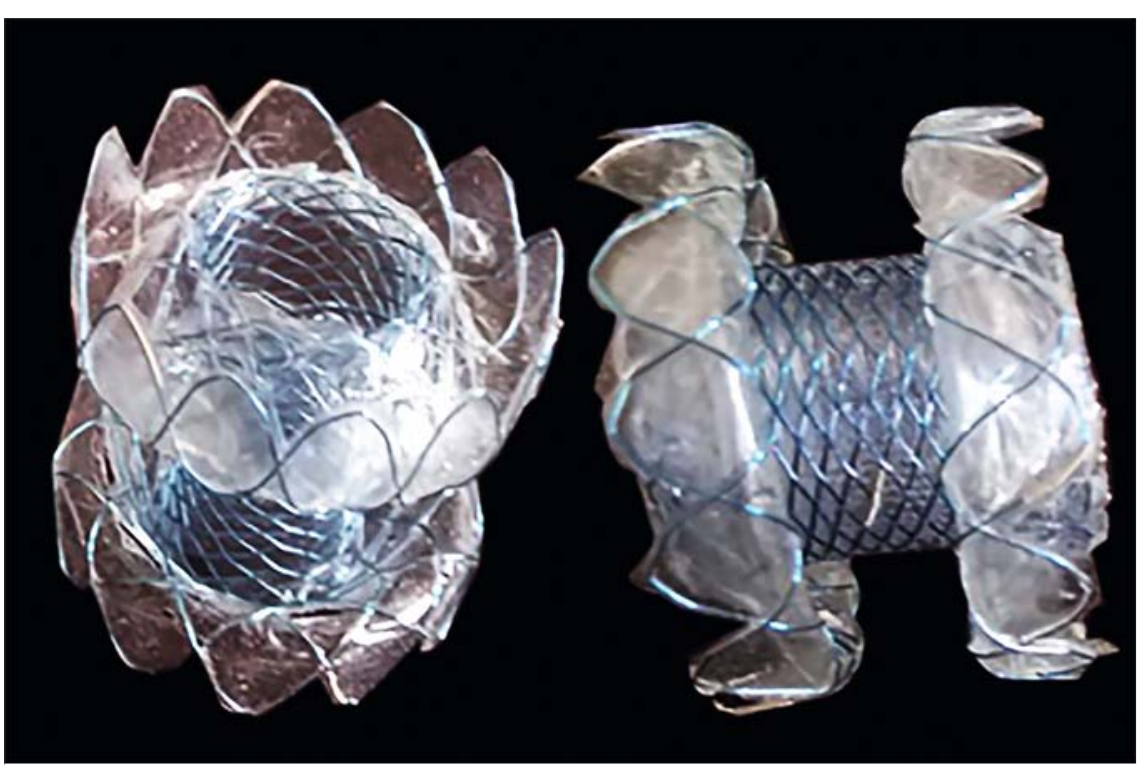

Fig. 2 The lumen-apposing fully covered metal stent (Spaxus; Taewoong Medical Co., Gyeonggi-do, South Korea).

stent placement can be considered as a strategy to avoid surgery, with its attendant risks of morbidity and mortality. Placement of lumen-apposing stents for treatment of short stenoses is technically easy, and safe. Furthermore, the Spaxus architecture helps to prevent migration, which occurs at a high rate when using conventional fully covered metal stents.

Endoscopy_UCTN_Code_TTT_1AO_2AZ
Competing interests

None

The Authors

Antonino Granata, Michele Amata, Dario Ligresti, Ilaria Tarantino, Luca Barresi, Mario Traina

Digestive Endoscopy Service, Department of Diagnostic and Therapeutic Services, IRCCS ISMETT, Palermo, Italy
Corresponding author

\section{Antonino Granata, MD}

Digestive Endoscopy Service, Department of Diagnostic and Therapeutic Services, IRCCS - ISMETT, Via Tricomi, 5, 90127

Palermo, Italy

Fax: +39-091-2192400

agranata@ismett.edu

\section{Bibliography}

DOI https://doi.org/10.1055/s-0043-117602

Published online: 10.8.2017

Endoscopy 2017; 49: E273-E274

(c) Georg Thieme Verlag KG

Stuttgart · New York

ISSN 0013-726X

\section{ENDOSCOPY E-VIDEOS}

https:/|eref.thieme.de/e-videos

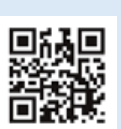

Endoscopy E-Videos is a free access online section, reporting on interesting cases and new techniques in gastroenterological endoscopy. All papers include a high quality video and all contributions are freely accessible online.

This section has its own submission website at

https://mc.manuscriptcentral.com/e-videos 